\title{
EFEITO DA SUBSTITUIC̃̃̃ DO FARELO DE SOJA PELA AMIRÉIA 150S NO CONSUMO, PRODUÇÃ̃O E COMPOSIÇÃO DO LEITE ${ }^{1}$
}

\author{
Effect of the substitution of the soybean meal for the starea $150 \mathrm{~S}$ in the intake, \\ production and composition of the milk
}

\author{
Flávio Garcia Vilela², Júlio César Teixeira ${ }^{3}$, Juan Ramon O. Pérez ${ }^{3}$, Paulo César de Aguiar Paiva ${ }^{3}$, \\ Joel Augusto Muniz ${ }^{4}$, Sidnei Tavares Reis ${ }^{5}$
}

\begin{abstract}
RESUMO
Doze vacas leiteiras $(3 / 4$ Holandês $\mathrm{x} 1 / 4$ Gir) foram utilizadas em um delineamento em quadrado latino, nas dependências da Fazenda Raposo - Nepomuceno, MG, entre novembro de 2001 e abril de 2002 para comparar o efeito da substituição parcial e total do farelo de soja pela amiréia na produção e composição do leite. Os animais apresentavam peso médio de $443 \mathrm{~kg}$ e estavam na quarta lactação. A amiréia substituiu o farelo de soja nas seguintes proporções: 0 - 0\% de amiréia 150 S; 33 - 33\% de amiréia 150 S; 66 - 66\% de amiréia $150 \mathrm{~S}$ e $100-100 \%$ de amiréia $150 \mathrm{~S}$, sendo que todos tratamentos foram isoenergéticos e isoprotéicos. Utilizou-se a canade-açúcar (Saccharum officinarum L.) como volumoso “ad libitum”. Cada período experimental teve duração de 15 dias, 9 dias para adaptação e 6 dias para coleta de dados. A produção de leite de cada vaca foi pesada nas duas ordenhas (manhã e tarde) e as amostras enviadas para análise de gordura, proteína, lactose, sólidos totais e uréia, pelo processo de infravermelho, junto à Clínica do Leite do Departamento de Produção Animal da ESALQ/USP. A gordura e sólidos totais do leite não foram influenciados pelos tratamentos $(\mathrm{P}>0,05)$. A produção de leite, a proteína, a lactose e a uréia do leite diferiram entre os tratamentos $(\mathrm{P}<0,05)$. Conclui-se que, nas condições deste experimento, é viável a substituição total do farelo de soja pela amiréia.
\end{abstract}

Termos para indexação: Amiréia, leite, consumo, produção.

\section{ABSTRACT}

Twelve dairy cows $(3 / 4$ Hoslten $\mathrm{x} / 4$ Gir) were used in a desing in Latin square, at Fazenda Raposo's dependences in Nepomuceno, MG, between November of 2001 and April of 2002 to compare the effect of the partial and total substitution of soybean meal for starea in the production and composition of milk. The medium weight of the animals was $443 \mathrm{~kg}$ and they were in the fourth nursing. The starea substituted soybean meal in the following proportions: 0 - $0 \%$ of starea $150 \mathrm{~S}$; $33-33 \% \%$ of starea $150 \mathrm{~S} ; 66-66 \%$ of starea $150 \mathrm{~S}$ and $100-100 \%$ of starea $150 \mathrm{~S}$, and every treatments were isoenergetics and isoproteics. Sugar-cane (Saccharum officinarum L.) was used ad libitum as roughage. Each experimental period had the duration of 15 days being 9 days for adaptation and 6 days for collection of data. The milk production of each cow was weighed twice a day (morning and afternoon) and samples were sent for analysis of fat, protein, lactose, total solids and urea, by the infrared method, at the Clinic of the Milk of the Department of Animal Production at ESALQ/USP, in Piracicaba, SP. Fat and total solids of milk were not influenced by the treatments. The production of milk, protein, lactose and urea content of milk differed among the treatments $(\mathrm{P}<0.05)$. The results showed that it is viable the total substitution of soybean meal for starea.

Index terms: Starea, intake, milk production.

(Recebido em 17 de dezembro de 2003 e aprovado em 8 de junho de 2006)

\section{INTRODUÇÃO}

O princípio de suplementação com fontes protéicas resistentes à degradação ruminal, para serem digeridas no intestino delgado do ruminante, com o objetivo de complementar a proteína microbiana, e assim aumentar a disponibilidade de aminoácidos essenciais para o animal, foi bem aceito por nutricionistas e pesquisadores, principalmente após a publicação do "Absorbed Protein
Model" pelo National Research Council (NRC, 1985). O modelo proposto pelo NRC (1985) representou um avanço em relação ao sistema de proteína bruta $(\mathrm{PB})$ e sem dúvida, que a partir de então, um maior refinamento foi introduzido na formulação de dietas para vacas leiteiras. Entretanto, segundo Santos et al. (1998a), a simples prática de substituir fontes tradicionais de proteína, como o farelo de soja, o qual é rico em proteína degradável no rúmen (PDR), por

${ }^{1}$ Parte de Tese do primeiro autor apresentada à Universidade Federal de Lavras para obtenção do Título de Doutor.

${ }^{2}$ Doutor - Nutrição de Ruminantes - Universidade de São Paulo/USP - Av. Duque de Caxias Norte, 225 - 13635-900 - Pirassununga, SP fgvilela@uai.com.br

32Doutor, Departamento de Zootecnia/DZO - Universidade Federal de Lavras/UFLA - Cx. P. 3037 - $37200-000$ - Lavras, MG - jperez@ufla.br; pcapaiva@ufla.br

${ }^{4}$ Doutor - Departamento de Ciências Exatas/DEX - Universidade Federal de Lavras/UFLA - Cx. P. 3037 - 37200-000 - Lavras, MG - joaomuniz@ufla.br ${ }^{5}$ Doutor - Departamento de Ciências Agrárias - Centro de Ciências Exatas e Tecnológicas/ CCET - Universidade Estadual de Montes Claros/UNIMONTES Rua Reinaldo Viana, 2630, Bico da Pedra - 39440-000 - Janaúba, MG - streis@uai.com.br 
fontes ricas em proteína não degradável no rúmen (PNDR), com o objetivo único de aumentar o teor de PNDR da dieta, não trouxe os resultados esperados em termos de produção e composição de leite. Isto levou a um questionamento quanto à recomendação de suplementação com proteína protegida, tendo como único critério a degradabilidade ruminal da fonte protéica.

A utilização de fontes de nitrogênio de baixo custo, como a uréia, não teve efeito negativo no desempenho de vacas com produção diária entre 30 a 36 litros de leite, principalmente quando combinada com fontes ricas em amido degradável no rúmen, de acordo com Santos et al. (1998a, b), apesar da proposta ser contrária a tendência de utilização de fontes ricas em PNDR, o que mostra a necessidade do aprofundamento do conhecimento sobre a combinação de fontes protéicas e energéticas para maximizar a disponibilidade de energia e aminoácidos para a vaca leiteira.

Assim, objetivou-se com o presente trabalho avaliar o efeito da substituição do farelo de soja pela amiréia $150 \mathrm{~S}$ no consumo, produção e composição do leite de vacas no início de lactação.

\section{MATERIAL E MÉTODOS}

O trabalho foi conduzido nas instalações da Fazenda Raposo - Nepomuceno, MG, entre os meses de novembro de 2001 e abril de 2002. As instalações constavam de baias individuais providas de comedouros, bebedouros e cochos próprios para suplementação mineral.

Foram utilizadas 12 vacas $(3 / 4$ Holândes $\mathrm{x} / 4$ Gir) em início de lactação (80 dias) com peso médio de $443 \mathrm{~kg}$ e produção de leite média de $13,10 \mathrm{~kg} /$ dia. Todos os animais estavam na quarta lactação.

O trabalho experimental foi delineado para estudar a inclusão parcial e total da amiréia na dieta de vacas em lactação. Os tratamentos foram isoenergéticos e isoproteícos e consistiram da substituição da proteína do farelo de soja pela amiréia 150S (53,33\% uréia, 44\% milho e $2,67 \%$ enxofre), nos seguintes níveis: $0-0 \%$ de amiréia $150 \mathrm{~S}$ em substituição da proteína do farelo de soja; 33 $33 \%$ de amiréia $150 \mathrm{~S}$ em substituição da proteína do farelo de soja; 66 - 66\% de amiréia $150 \mathrm{~S}$ em substituição da proteína do farelo de soja; 100 - 100\% de amiréia 150 S em substituição da proteína do farelo de soja.

A alimentação dos animais consistiu de cana-deaçúcar fornecida ad libitum e $5 \mathrm{~kg}$ de concentrado/vaca/ dia (1 kg concentrado/3 litros de leite). As dietas experimentais e sua composição química em função dos níveis de amiréia encontram-se nas Tabelas 1 e 2.

O período experimental teve duração de 180 dias (4 períodos x 15 dias em 3 QL seqüenciais). Todas as vacas foram pesadas no início e no final do experimento.

Os animais foram ordenhados 2 vezes ao dia, às 6:00 e 17:00 horas e as produções individuais de leite pesadas em balanças eletrônicas durante todos os 6 dias de coleta. As amostras de leite de cada vaca foram enviadas para análise de gordura, proteína, lactose, sólidos totais e uréia, pelo processo infravermelho, junto à Clínica do Leite do Departamento de Produção Animal da ESALQ/USP.

As vacas foram também alimentadas 2 vezes ao dia às 6:00 e 17:00 horas e as sobras de alimento pesadas e descartadas diariamente.

TABELA 1 - Concentrados experimentais em função dos níveis de substituição do farelo de soja pela amiréia 150S.

\begin{tabular}{lrrrr}
\hline \multirow{2}{*}{ Ingredientes } & \multicolumn{4}{c}{ Níveis de substituição (\%) } \\
\cline { 2 - 5 } & $\mathbf{0}$ & $\mathbf{3 3}$ & $\mathbf{6 6}$ & $\mathbf{1 0 0}$ \\
\hline Fubá de milho & 55,40 & 65,53 & 69,80 & 82,00 \\
Amiréia 150 S & 0,00 & 4,20 & 5,90 & 11,10 \\
Farelo de soja & 42,30 & 26,30 & 19,70 & 0,00 \\
Gordura animal & 0,05 & 1,50 & 2,00 & 4,00 \\
Calcário & 0,85 & 0,72 & 0,65 & 0,50 \\
Fosfato bicálcico & 0,30 & 0,65 & 0,85 & 1,30 \\
Sal comum & 0,30 & 0,30 & 0,30 & 0,30 \\
Premix mineral & 0,30 & 0,30 & 0,30 & 0,30 \\
Premix vitamínico & 0,30 & 0,30 & 0,30 & 0,30 \\
Enxofre em pó & 0,20 & 0,20 & 0,20 & 0,20 \\
\hline \multicolumn{1}{c}{ Total } & 100,00 & 100,00 & 100,00 & 100,00 \\
\hline
\end{tabular}


TABELA 2 - Composição dos concentrados experimentais em função dos níveis de substituição do farelo de soja pela amiréia $150 \mathrm{~S}$.

\begin{tabular}{|c|c|c|c|c|}
\hline \multirow{2}{*}{ Nutrientes (\%) } & \multicolumn{4}{|c|}{ Níveis de substituição (\%) } \\
\hline & $\mathbf{0}$ & 33 & 66 & 100 \\
\hline Matéria seca (MS) & 90,00 & 90,00 & 90,00 & 90,00 \\
\hline Proteína bruta (PB) & 24,02 & 24,03 & 24,00 & 24,03 \\
\hline PB do farelo de soja & 19,04 & 11,84 & 8,87 & 0,00 \\
\hline PB da amiréia & 0,00 & 6,30 & 8,85 & 16,65 \\
\hline Nutrientes digestíveis totais (NDT) & 77,40 & 76,90 & 76,58 & 76,13 \\
\hline Fibra detergente neutro (FDN) & 9,34 & 8,69 & 8,43 & 7,60 \\
\hline Fibra em detergente ácido (FDA) & 5,94 & 5,06 & 4,70 & 3,61 \\
\hline Extrato etéreo (EE) & 2,77 & 4,58 & 5,24 & 7,67 \\
\hline Carboidratos totais $(\mathrm{CHT})^{1}$ & 68,94 & 71,03 & 71,96 & 74,30 \\
\hline Carboidratos estruturais $(\mathrm{CE})^{1}$ & 9,34 & 9,03 & 8,91 & 8,49 \\
\hline $\begin{array}{l}\text { Carboidratos não estruturais } \\
(\mathrm{CNE})^{1}\end{array}$ & 59,60 & 62,00 & 63,05 & 65,81 \\
\hline Amido $^{1}$ & 43,11 & 51,51 & 55,03 & 65,16 \\
\hline Cálcio (Ca) & 0,54 & 0,54 & 0,54 & 0,54 \\
\hline Fósforo (P) & 0,50 & 0,49 & 0,50 & 0,49 \\
\hline Nitrogênio não protéico (NNP) & 1,55 & 1,97 & 2,14 & 2,66 \\
\hline
\end{tabular}

${ }^{1}$ Calculado segundo metodologia descrita por Sniffen et al. (1992).

As amostras da cana-de-açúcar e dos concentrados foram analisadas para matéria seca $(\mathrm{MS})$, proteína bruta (PB), extrato etéreo (EE), cálcio $(\mathrm{Ca})$ e fósforo $(\mathrm{P})$, segundo metodologia descrita por Silva (1990). Utilizou-se os métodos descritos por Soest et al. (1991) para determinação da FDN e FDA dos alimentos.

O delineamento experimental utilizado foi o quadrado latino, com 4 períodos experimentais (15 dias), 4 tratamentos e 4 animais.

Foram utilizados 3 quadrados latinos (1 QL -nov. e dez./2001; 2으 QL - jan. e fev./2002; 3ํQ - mar. e abr./2002) com duração de 2 meses cada, sendo que cada animal teve 9 dias de adaptação e 6 dias de coleta para o estudo do consumo, produção e composição do leite. Os dados obtidos para tais variáveis foram submetidos à análise de variância (ANOVA) e quando significativos submetidos a estudo de regressão, segundo o procedimento "GLM" do Software Statistical Analysis System (SAS INSTITUTE, 1991).

\section{RESULTADOS E DISCUSSÃO}

Os resultados para consumo de matéria seca, proteína bruta, fibra em detergente neutro, indicam que houve diferença significativa $(\mathrm{P}<0,05)$ entre os níveis de amiréia utilizados .

As médias referentes ao consumo diário da matéria seca, proteína bruta e FDN, expressos em kg/ dia, g/ $/ \mathrm{kg}^{0,75} / \mathrm{dia}$ e $\%$ do peso vivo, estão apresentados na Tabela 3. Observa-se na Figuras 1 e 2 que os dados em relação ao consumo de proteína bruta $(\mathrm{kg} / \mathrm{dia})$ e consumo de FDN (\% do PV/dia) são explicados pela regressão quadrática cujo estudo permite estabelecer os níveis ótimos de substituição do farelo de soja pela amiréia, obtidos por meio da derivada simples da equação de regressão, sendo os mesmos de 30 e 36,66\%, respectivamente.

A ingestão média de FDN em relação ao peso vivo (\% PV) foi de 1,97\%, superior às obtidas por Aroeira et al. (1995) (1,6\% PV), que trabalharam com vacas mestiças Holandês x Zebu em lactação recebendo cana-de-açúcar + uréia e farelo de algodão.

Mertens (1994) verificou que em vacas leiteiras, em meio e final de lactação, o consumo de MS e a produção de leite foram máximos para consumo de FDN igual a 1,25\% do peso vivo. Dados encontrados por Silva et al. (2001) confirmam os índices observados. 
TABELA 3 - Consumo em função dos níveis de substituição do farelo de soja pela amiréia 150S.

\begin{tabular}{|c|c|c|c|c|c|}
\hline \multirow{2}{*}{ Consumo } & \multicolumn{4}{|c|}{ Níveis de substituição (\%) } & \multirow{2}{*}{ CV } \\
\hline & $\mathbf{0}$ & 33 & 66 & 100 & \\
\hline MS (kg/dia) & 15,29 & 15,39 & 15,42 & 14,69 & 2,76 \\
\hline MS (g MS/kg $\left.{ }^{0,75} / \mathrm{dia}\right)$ & 158,26 & 159,25 & 159,60 & 152,00 & 2,82 \\
\hline MS (\%PV/dia) & 3,44 & 3,47 & 3,48 & 3,31 & 2,82 \\
\hline PB (kg/dia) & 1,35 & 1,36 & 1,36 & 1,34 & 0,84 \\
\hline $\mathrm{PB}\left(\mathrm{g} \mathrm{PB} / \mathrm{kg}^{0,75} / \mathrm{dia}\right)$ & 14,05 & 14,08 & 14,09 & 13,89 & 0,82 \\
\hline $\mathrm{PB}(\% \mathrm{PV} / \mathrm{dia})$ & 0,30 & 0,31 & 0,31 & 0,30 & 1,28 \\
\hline FDN (kg/dia) & 8,38 & 8,93 & 8,95 & 8,33 & 3,76 \\
\hline FDN (g FDN/kg $\left./{ }^{0,75} / \mathrm{dia}\right)$ & 92,01 & 92,47 & 92,62 & 86,31 & 3,83 \\
\hline FDN (\%PV/dia) & 2,00 & 2,01 & 2,02 & 1,88 & 3,85 \\
\hline
\end{tabular}

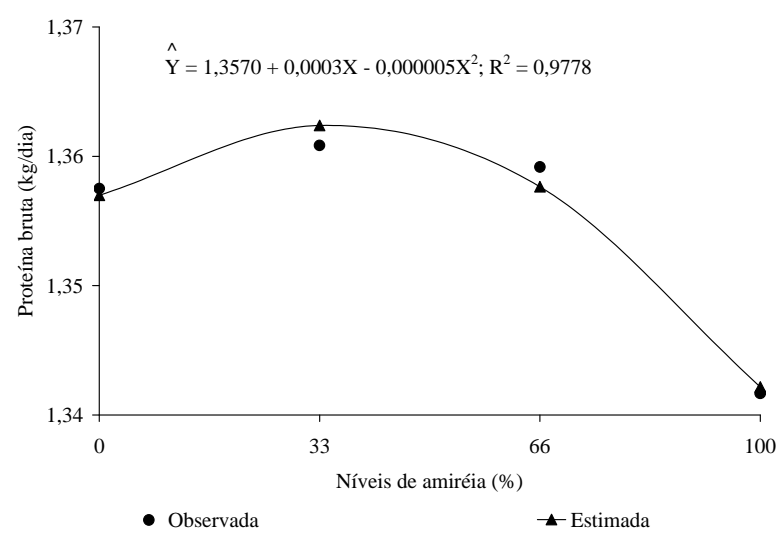

FIGURA 1 -Consumo de proteína bruta $(\mathrm{kg} / \mathrm{dia})$ em função dos níveis de substituição do farelo de soja pela amiréia $150 \mathrm{~S}$.

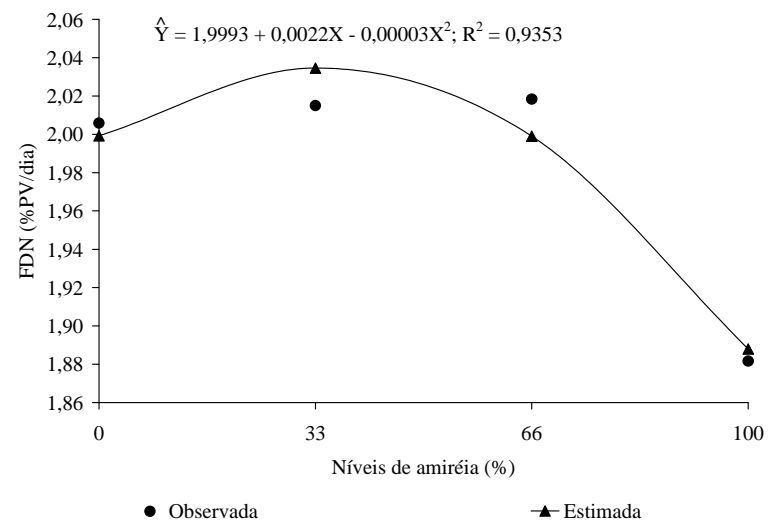

FIGURA 2 - Consumo de FDN (\% PV/dia) em função dos níveis de substituição do farelo de soja pela amiréia 150S.
Houve diferença significativa $(\mathrm{P}<0,05)$ entre os níveis de amiréia utilizados para produção de leite; proteína bruta, lactose e uréia do leite.

As médias referentes à produção de leite, leite corrigido a 4 e 3,5\%, bem como a composição do leite, estão apresentadas na Tabela 4. Observa-se na Figuras 3 que os dados em relação à produção de leite (kg/dia) são explicados pela regressão quadrática, cujo estudo permite estabelecer $35 \%$ como o nível ótimo de substituição da proteína do farelo de soja pela amiréia.

Neste experimento ocorreu uma diminuição na produção de leite após o nível de $35 \%$ de substituição (Figura 3), o que também foi verificado por Santos et al. (2001) ao substituir a proteína do farelo de soja pela uréia. Estes resultados, porém, discordam de diversos trabalhos em que o farelo de soja foi parcialmente substituído por uréia sem afetar a produção de leite (BRODERICK et al., 1993; JOHNSON et al., 1987; SANTOS, 1998).

Silva et al. (2001) utilizando vacas lactantes (Holandês x Gir) contendo até 2,1\% de uréia (MS) observaram diminuição na produção de leite corrigido a $3,5 \%$ de gordura com o aumento dos níveis de nitrogênio não protéico na ração, o que também foi verificado neste experimento. As menores ingestões de matéria seca com a elevação dos teores de nitrogênio não protéico neste experimento, poderiam implicar em menores produções de leite, verificadas principalmente no tratamento com $100 \%$ de amiréia.

As Figuras 4 a 6, mostram, respectivamente, uma diminuição linear $(\mathrm{P}<0,05)$ na proteína do leite $(\%)$ e um acréscimo linear $(\mathrm{P}<0,05)$ no nitrogênio uréico e uréia do leite $(\mathrm{mg} / \mathrm{dl})$. Com relação à proteína do leite $(\%)$, ocorreu uma diminuição, assim como verificado por Silva et al. (2001) (Figura 4). 
VILELA, F. G. et al.

TABELA 4 - Produção e composição do leite em função dos níveis de substituição do farelo de soja pela amiréia 150S.

\begin{tabular}{|c|c|c|c|c|c|}
\hline \multirow{2}{*}{ Produção } & \multicolumn{4}{|c|}{ Níveis de substituição (\%) } & \multirow{2}{*}{ CV } \\
\hline & $\mathbf{0}$ & 33 & 66 & 100 & \\
\hline Leite (kg/dia) & 13,35 & 13,22 & 13,48 & 12,36 & 3,37 \\
\hline Leite corrigido 4\% & 13,12 & 13,14 & 13,27 & 12,35 & 7,14 \\
\hline Leite corrigido $3,5 \%$ & 14,18 & 14,20 & 14,35 & 13,35 & 7,14 \\
\hline PB do leite $(\mathrm{kg})$ & 0,48 & 0,45 & 0,46 & 0,41 & 7,34 \\
\hline Lactose do leite (kg) & 0,60 & 0,61 & 0,57 & 0,57 & 6,21 \\
\hline Gordura do leite $(\mathrm{kg})$ & 0,52 & 0,53 & 0,53 & 0,50 & 7,50 \\
\hline Sólidos totais do leite $(\mathrm{kg})$ & 1,74 & 1,73 & 1,74 & 1,60 & 6,41 \\
\hline \multicolumn{6}{|l|}{ Composição } \\
\hline PB (\%) & 3,60 & 3,46 & 3,41 & 3,33 & 2,74 \\
\hline Lactose (\%) & 4,49 & 4,60 & 4,57 & 4,60 & 1,45 \\
\hline Gordura (\%) & 3,93 & 3,99 & 3,95 & 4,04 & 5,15 \\
\hline Sólidos totais (\%) & 13,04 & 13,08 & 12,93 & 12,96 & 1,77 \\
\hline Nitrogênio ureíco (mg/dl) & 5,53 & 5,34 & 7,00 & 8,36 & 15,87 \\
\hline Uréia $(\mathrm{mg} / \mathrm{dl})$ & 11,86 & 11,46 & 15,02 & 17,94 & 15,87 \\
\hline
\end{tabular}

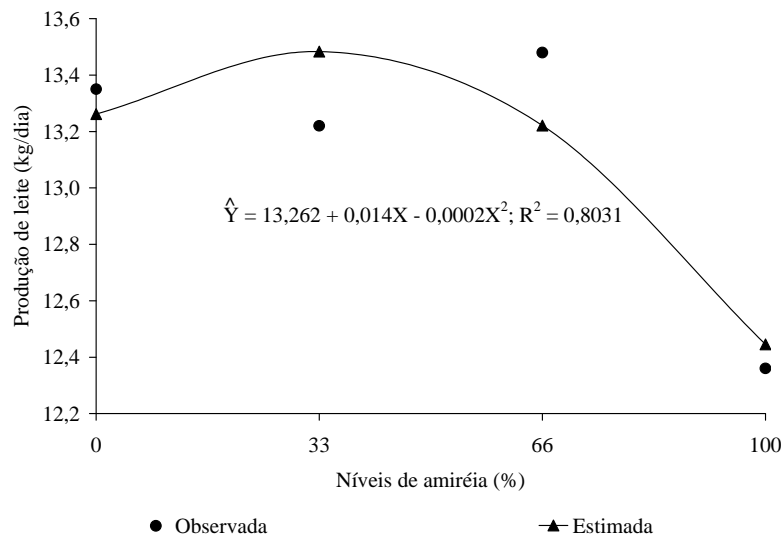

FIGURA 3 - Produção de leite (kg/dia) em função dos níveis de substituição do farelo de soja pela amiréia $150 \mathrm{~S}$.

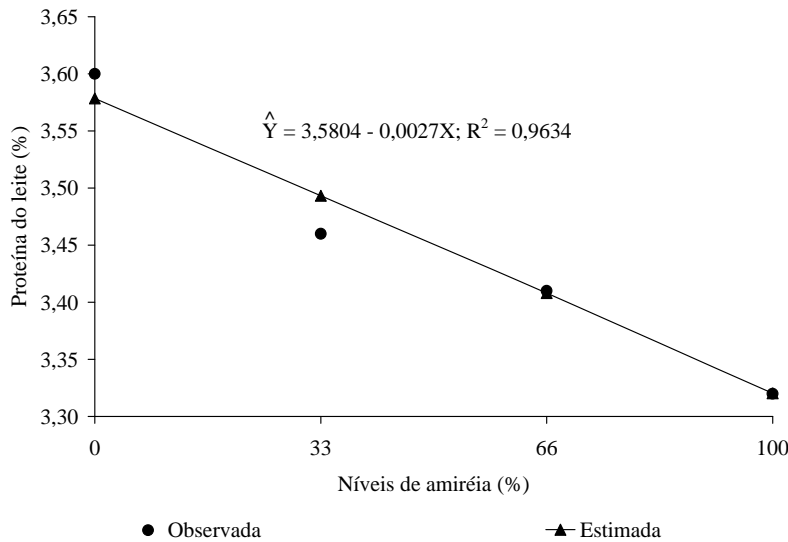

FIGURA 4 - Proteína do leite (\%) em função dos níveis de substituição do farelo de soja pela amiréia 150S.
Segundo Jonker et al. (1999), dietas com baixos níveis de energia e excesso dos requerimentos de proteína degradável no rúmen em relação às exigências da vaca podem resultar em decréscimo na produção de leite e, conseqüentemente, da secreção de proteína do mesmo. De acordo com Roseler et al. (1993), a produção de proteína do leite foi positivamente relacionado à produção do leite, o que também foi evidenciado neste experimento.

As concentrações médias de uréia e nitrogênio uréico no leite neste experimento foram de 14,07 e $6,55 \mathrm{mg} / \mathrm{dl}$, respectivamente (Figuras 5 e 6), apresentando valores inferiores aos relatados por Oliveira et al. (2001), de 54,61 e $25,45 \mathrm{mg} / \mathrm{dl}$, que trabalharam com rações isoproteícas e níveis crescentes de uréia $(0 ; 0,6 ; 1,4$ e 2,1\%) para vacas holandesas.

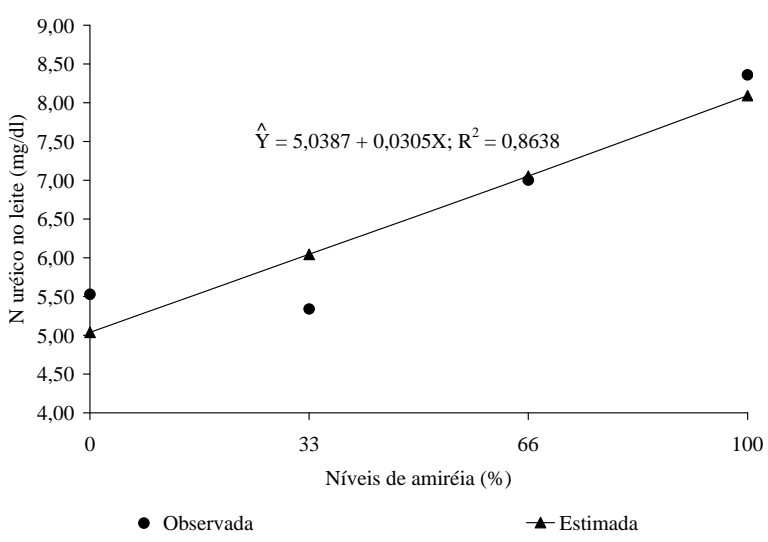

FIGURA 5 - Nitrogênio uréico no leite $(\mathrm{mg} / \mathrm{dl})$ em função dos níveis de substituição do farelo de soja pela amiréia 150S. 


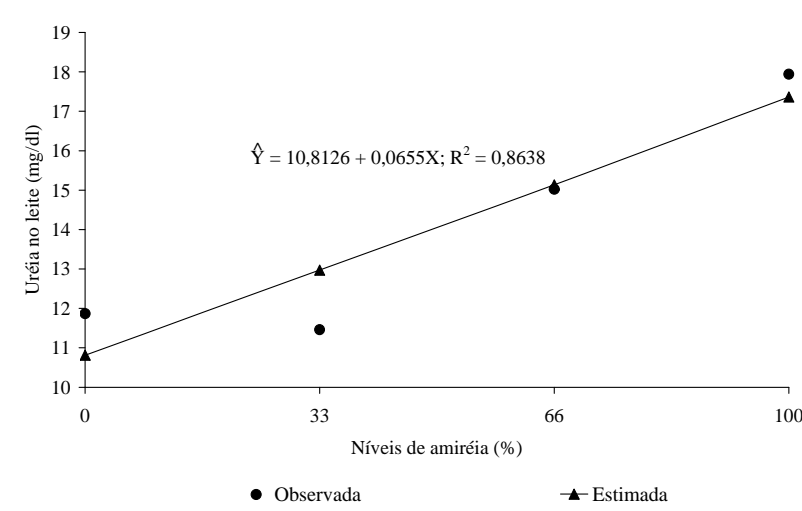

FIGURA 6 - Uréia no leite $(\mathrm{mg} / \mathrm{dl})$ em função dos níveis de substituição do farelo de soja pela amiréia 150S.

Segundo Jobim \& Santos (2000), os valores médios de uréia no leite enquadram na faixa de $12-18 \mathrm{mg} / \mathrm{dl}$, o que assemelham-se aos resultados descritos neste estudo.

Os conteúdos de uréia do leite diferiram entre os níveis de amiréia e também mostraram valores próximos aos relatados em outros trabalhos da literatura. Os resultados reportados por Baker et al. (1995) mostraram valores entre 15 e 23 mg/dl; DePeters \& Cant (1992), em sua revisão, apresentaram um valor médio de $17 \mathrm{mg} / \mathrm{dl}$ e Wolfschoon-Pombo \& Regner (1982), comparando dois métodos diferentes para determinação da uréia no leite, obtiveram valor médio de $14,3 \mathrm{mg} / \mathrm{dl}$.

Assim como ocorreu neste experimento, Broderick et al. (1993) e Johnson et al. (1987) também não observaram nenhum efeito da uréia no teor de gordura do leite. Os trabalhos revisados por Santos et al. (1998b) também não mostraram efeito da suplementação com uréia no teor de gordura do leite de vacas produzindo entre 20 e $41 \mathrm{~kg}$ de leite/dia.

Não houve diferença significativa $(\mathrm{P}>0,05)$ entre os tratamentos com relação ao teor dos sólidos totais (\%), o que também foi verificado por Pereira et al. (2001), que trabalharam com diferentes fontes de proteína em substituição parcial à fonte protéica de uma dieta controle à base de farelo de soja.

\section{CONCLUSÕES}

Conclui-se que todos os tratamentos, nos níveis de inclusão estudados, podem ser seguramente utilizados sem qualquer prejuízo à composição do leite.

Com relação à produção de leite, conclui-se um nível ótimo de $35 \%$ de substituição da proteína do farelo de soja pela amiréia.

\section{REFERÊNCIAS BIBLIOGRÁFICAS}

AROEIRA, L. J. M.; LOPES, F. C. F.; DAYRELL, M. S.; LIZIEEIRE, R. S.; TORRES, M. P. Digestibilidade, degradabilidade e taxa de passagem da cana-de-açúcar mais uréia e do farelo de algodão em vacas mestiças holandês $\mathrm{x}$ zebu em lactação. Revista da Sociedade Brasileira de Zootecnia, Viçosa, v. 24, n. 6, p. 1016-1026, jun. 1995.

BAKER, L. D.; FERGUSON, J. D.; CHALUPA, W. Responses in urea and true protein of milk to different protein feeding schemes for dairy cows. Journal of Dairy Science, Champaign, v. 78, n. 11, p. 2424-2434, Nov. 1995.

BRODERICK, G. A.; CRAIG, W. M.; RICKER, D. B. Urea versus true protein as supplement for lactating dairy cows fed grains plus mixtures of alfafa and corn silages. Journal of Dairy Science, Champaign, v. 76, n. 8, p. 2266-2274, Aug. 1993.

DePETERS, E. J.; CANT, J. P. Nutritional factors influencing the nitrogen composition of bovine milk: a review. Journal of Dairy Science, Champaign, v. 75, n. 8, p. 20432070, Aug. 1992.

JOBIM, C. C.; SANTOS, G. T. Influência da qualidade de forragens conservadas sobre a qualidade do leite de vacas. In: WORKSHOP SOBRE PRODUÇÃO E QUALIDADE DO LEITE, 2., 2000, Maringá. Anais... Maringá: UFPR, 2000. p. $1-9$.

JOHNSON, C. O. L. E.; HUBER, J. T.; KING, K. J. Storage and utilization of brewers wet grains in diets for lactating dairy cows. Journal of Dairy Science, Champaign, v. 70, n. 1, p. 98-107, Jan. 1987.

JONKER, J. S.; KOHN, R. A.; ERDMAN, R. A. Milk urea nitrogen target concentrations of lactating dairy cows fed according to National Research Council recommendations. Journal of Dairy Science, Champaign, v. 82, n. 6, p. 12611273, June 1999.

MERTENS, D. R. Regulation of forage intake. In: FAHEY JUNIOR, G. C. (Ed.). Forage quality, evaluation and utilization. Madison: American Society of Agronomy, 1994. p. $450-493$.

NATIONAL RESEARCH COUNCIL. Ruminant nitrogen usage. Washington, DC: National Academy, 1985. 138 p. 
OLIVEIRA, A. S.; VALADARES, R. F. D.; RENNÓ, L. N.; QUEIROZ, A. C.; CHIZZOTI, M. L. Produção de proteína microbiana e estimativas das excreções de derivados de purinas e de uréia em vacas lactantes alimentadas com rações isoprotéicas contendo diferentes níveis de compostos nitrogenados não-protéicos. Revista Brasileira de Zootecnia, Viçosa, v. 30, n. 5, p. 1621-1629, set./out. 2001.

PEREIRA, A. M.; PÉREZ, J. R. O.; TEIXEIRA, J. C.; ABREU, L. R. de J. A. Influência da fonte de proteína da dieta total na composição do leite de vacas holandesas. Ciência e Agrotecnologia, Lavras, v. 25, n. 6, p. 1446-1456, nov./dez. 2001.

ROSELER, D. K.; FERGUNSON, J. D.; SNIFFEN, C. J.; HERREMA, J. Dietary protein degradability effects on plasma and milk urea nitrogen and milk nonprotein nitrogen in Holstein cows. Journal of Dairy Science, Champaign, v. 76, n. 2, p. 525-534, Feb. 1993.

SANTOS, F. A. P. Efeito de fontes protéicas e processamento de grãos no desempenho de vacas de leite e digestibilidade dos nutrientes. 1998. 105 f. Tese (Livre Docência) - Escola Superior de Agricultura Luiz de Queiroz, Universidade de São Paulo, Piracicaba, 1998.

SANTOS, F. A. P.; HUBER, J. T.; THEURER, C. B. Milk yield and composition of lactating cows fed steam-flaked sorghum and graded concentrations of ruminally degradable protein. Journal of Dairy Science, Champaign, v. 81 , n. 1, p. 215-220, Jan. 1998a.

SANTOS, F. A. P.; JUCHEM, S. O.; IMAIZUMI, H. Suplementação de fontes de proteína e de amido com diferentes degradabilidades ruminais para vacas em lactação. In: REUNIÃO ANUAL DA SOCIEDADE
BRASILEIRA DE ZOOTECNIA, 37., 2001, Piracicaba. Anais... Piracicaba: FEALQ, 2001.

SANTOS, F. A. P.; SANTOS, J. E. P.; THEURER, C. B.; HUBER, J. T. Effects of rumen undegradable protein on dairy cow performance: a 12-year literature review. Journal of Dairy Science, Champaign, v. 81, n. 12, p. 3182-3213, Dec. 1998 b

SAS INSTITUTE. SAS user's guide: statistics. 5. ed. Cary, 1991. $1290 \mathrm{p}$.

SILVA, D. J. Análise de alimentos: métodos químicos e biológicos. Viçosa: UFV, 1990. $196 \mathrm{p}$.

SILVA, R. M. N. da; EZEQUIEL, J. M. B.; GALATI, R. L. Uréia para vacas em lactação: 1- consumo, digestibilidade, produção e composição do leite. Revista Brasileira de Zootecnia, Viçosa, v. 30, n. 5, p. 1639-1649, maio 2001.

SNIFFEN, C. J.; O’CONNOR, J. D.; SOEST, P. J. van; FOX, D. E.; RUSSEL, J. B. A net carbohydrate and protein system for evaluation cattle diets: II. carbohydrate and protein availability. Journal of Animal Science, Champaign, v. 70, n. 12 , p. 3562-2577, Dec. 1992.

SOEST, P. J. van; ROBERTSON, J. B.; LEWIS, B. A. Methods for dietary fiber, neutral detergent fiber and non starch polysaccharides in relation to animal nutrition. Journal of Animal Science, Champaign, v. 71, n. 10, p. 3583-3597, Oct. 1991.

WOLFSCHOON-POMBO, A. F.; REGNER, P. Determinação do teor de uréia em produtos lácteos. Revista do Instituto de Laticínios Cândido Tostes, Juiz de Fora, v. 220, n. 37, p. 21-23, mar./abr. 1982. 